Article

\title{
Photoconversion Fluoropolymer Films for the Cultivation of Agricultural Plants Under Conditions of Insufficient Insolation
}

\author{
Alexander V. Simakin ${ }^{1}$, Veronika V. Ivanyuk ${ }^{1}$, Alexey S. Dorokhov ${ }^{2}$ and Sergey V. Gudkov ${ }^{1, *(\mathbb{D})}$ \\ 1 Biophotonics Center, Prokhorov General Physics Institute of the Russian Academy of Sciences, \\ 38 Vavilova St., 119991 Moscow, Russia; simakin.a@yahoo.com (A.V.S.); veronika.ivaniuk@yandex.ru (V.V.I.) \\ 2 Department of Closed Artificial Agroecosystems for Crop Production, Federal State Budgetary Scientific \\ Institution "Federal Scientific Agroengineering Center VIM" (FSAC VIM), 5 First Institutskiy pr-d, \\ 109428 Moscow, Russia; dorokhov@rgau-msha.ru \\ * Correspondence: S_makariy@rambler.ru
}

Received: 14 October 2020; Accepted: 11 November 2020; Published: 12 November 2020

\begin{abstract}
Plants are capable of using mainly the quanta of the red and blue parts of a spectrum for the reception of energy during photosynthesis. However, for many crops grown indoors in high latitudes or under conditions of insufficient insolation, the average daily intensity of the red and blue parts of the spectrum is usually sufficient only on clear summer days. A technology has been proposed to produce a photoconversion fluoropolymer film for greenhouses, which is based on the modification of fluoropolymer by nanoparticles with fluorescence in the blue or red part of the spectrum (quantum dots). The films are capable of converting UV and violet radiation into the blue and red region of the visible spectrum, the most important for plants. It has been shown that the use of photoconversion fluoropolymer films promotes biomass growth. The area of cucumber leaves grown under photoconversion films increases by $20 \%$, pumpkins by $25 \%$, pepper by $30 \%$, and tomatoes by $55 \%$. The use of photoconversion fluoropolymer films for greenhouses also allows obtaining $15 \%$ more fruit biomass from one bush. In general, the use of photoconversion fluoropolymer films may be in great demand for greenhouses lying in high latitudes and located in areas with insufficient insolation.
\end{abstract}

Keywords: photoconversion; quantum dots; nanomaterials; greenhouses; protected grounds; insufficient insolation

\section{Introduction}

For most ecological systems, visible light, which occupies the range of electromagnetic radiation wavelengths of $380-780 \mathrm{~nm}$ and quantum energies of 1.6-3.2 eV, is the main source of energy [1]. Visible light is extremely important for the existence of life on Earth [2]. The fact is that visible light is the main source of energy in most biosystems [3]. The transformation of the energy of light quanta into the energy of chemical bonds occurs in the process of photosynthesis, for this, higher plants mainly need light in the red and blue regions of the spectrum [4]. Visible light is necessary not only for plants, but also affects representatives of other Kingdoms of living beings (animals, fungi, and microorganisms) [5-7]. In particular, for the existence of most biological species, such processes as vision, phototropisms, photonastia, etc. are important. In general, light of different wavelength ranges has an important signal-regulatory effect on biological objects [8]. It has long been known for plants that changes in light intensity in different spectral ranges (UV, visible, and near-IR radiation) can significantly affect productivity and physiological status [9]. Observations of these processes were begun in antiquity. After the invention of absorption filters, researchers actively studied the effect of various ranges of visible radiation on biological objects. A large amount of information was accumulated, and the 
main regularities obtained were confirmed after the creation of monochromators [10]. Interestingly, one of the first three Nobel Prizes in Physiology or Medicine was awarded to Niels Finsen (1903) "in recognition of his services in the treatment of diseases-especially lupus-with concentrated light radiation, which opened up new broad horizons for medical science" [11]. After 1954, when the laser was invented, the era of research into the effect of laser radiation on biological objects began. "For fundamental work in the field of quantum electronics, which led to the creation of oscillators and amplifiers based on the maser-laser principle," the Nobel Prize was awarded to Alexander Prokhorov, Nikolai Basov, and Charles Townes [12]. Currently, laser radiation sources are largely replaced by LED illuminators (Light-emitting diodes) [13].

On the whole, photobiology has gone through two important stages: 1 . Changing the spectrum of the sun, and 2. Creation of light sources. The second stage involves the use of precision light sources; in this case, accuracy is important. This approach has found wide application in medicine and biology. The first approach allows you to ensure mass scale, and the approach is based on the following principle: absorption of light quanta of broadband radiation occurs in one spectral window, and re-emission of quanta occurs in another, narrower spectral window. The main drivers of photoconversion technologies are theranostics, biophotonics, and a number of areas of physics associated with the creation of devices operating on the basis of sunlight (solar batteries, electrophotosynthesis cells, etc.) [14-16]. The scope of attempts to apply photoconversion technologies in agriculture is often limited to greenhouses. It is known that for most plants, red $(645-715 \mathrm{~nm})$ rays are of the greatest importance [17]. It is the quanta of red light that provide the main energy input to the process of photosynthesis. In addition, the quanta of red light affect the processes of plant development, for example, an increase in intensity in the red and orange parts of the spectrum delays the transition of a plant to flowering [18]. The quanta of blue and violet (380-490 $\mathrm{nm}$ ) light are also directly involved in the process of photosynthesis [19]. In addition, blue light stimulates the production of proteins and is involved in the regulation of plant development [20]. In plants growing under conditions of insufficient insolation, an increase in the blue component in the solar spectrum leads to flowering [18]. Yellow (595-565 nm) and green $(565-490 \mathrm{~nm})$ rays are absorbed by various carotenoids. This spectral range does not significantly affect the life of cultivated plants. In nature, light in the yellow and green ranges is mainly important for shade-loving plants growing in the lower tiers of forests, as well as for some aquatic plants [21]. UV radiation also does not play a significant role in the life of cultivated plants; it should be noted that in the solar spectrum only $1-2 \%$ of the energy falls on UV radiation photons [22]. Based on the above, in greenhouses under conditions of insufficient insolation, the most logical would be the photoconversion of UV radiation, green and yellow light, into blue and red light [23].

Currently, many greenhouse coatings have been developed that carry out partial photoconversion [24-26]. Earlier in our Biophotonics centre, based on quantum dots and gold nanoparticles, a photoconversion coating was developed for greenhouses located in the Arctic regions [27]. The nanoparticles in the polymer were arranged in the form of linear aggregates (like beads), which made it possible to significantly enhance the field of the optical wave. In this case, the absorption in the plasmon resonance line of gold nanoparticles (green region of the spectrum) increased several times, which ultimately leads to a significant heating of the polymer. In addition to heating, the polymer is capable of photoconversion, including the red region of the spectrum that is important for plants productivity (maximum emission at $630 \mathrm{~nm}$ ). It has been shown that these polymer films are capable of accelerating the growth of a number of crops at the initial stages of development at low temperatures. In this work, photoconversion films based on the highly resistant and vapor-proof fluoropolymer LF-32LN have been created. These films are not capable of heating; nanoparticles in these films do not form linear aggregates in the form of beads, they are evenly spaced. In this work, a quantum dots with quantum yield of more than $20 \%$ was synthesized, with emission in the blue $\left(\lambda_{\max }=460 \mathrm{~nm}\right)$ and red $\left(\lambda_{\max }=650 \mathrm{~nm}\right)$ spectral regions. The fluorescence of the quantum dots we synthesized now overlaps with the spectral window of photosystem II of higher plants, which provides significant advantages. It is shown that the developed photoconversion films not only make it possible 
to increase the rate of plant development at an early stage, but also to obtain a larger yield. The use of the developed film could significantly increase the productivity of greenhouses located in conditions of insufficient average daily illumination.

\section{Materials and Methods}

\subsection{Preparation of Photoluminophor Nanoparticles and Investigation of Its Properties}

Photoluminophor nanoparticles in the form of $\mathrm{Cd}_{(1-\mathrm{x})} \mathrm{Zn}_{(\mathrm{x})}$ Se quantum dots were synthesized by injecting trioctylphosphine-Se into a metal solution at $320^{\circ} \mathrm{C}$. The solution contained a constant precursor ratio of $\mathrm{Cd} / \mathrm{Zn}=1 / 9$ and oleic acid and oleylamine surfactants in octadecene. The details of the technology for manufacturing $\mathrm{Cd}_{(1-\mathrm{x})} \mathrm{Zn}_{(\mathrm{x})}$ Se quantum dots were described earlier [28]. The advantage of this technology is the possibility of producing $\mathrm{Cd}_{(1-\mathrm{x})} \mathrm{Zn}_{(\mathrm{x})}$ Se quantum dots with a controlled $\mathrm{Cd} / \mathrm{Zn}$ ratio. For the manufacture of photoconversion composites, a $7 \%$ solution of quantum dots in acetone was used. The solution of nanoparticles was mixed with the liquid component of the fluoroplate polymer in a ratio of 1/100. Fluoroplast-32L (St. Petersburg Kraski, Russia) served as the basis for obtaining polymer varnish. Polymer LF-32LN from fluoroplastic 32L has a low degree of crystallinity, and is one of the best moisture-proof coatings (the moisture permeability of coatings from it is $0.16 \times 10-15 \mathrm{~kg} /(\mathrm{s} \times \mathrm{m} \times \mathrm{Pa})$, this is 30 times less than moisture permeability polyethylene, and 40-60 times less than the moisture permeability of epoxy varnishes. The resulting mixture was stirred for $10 \mathrm{~min}$ until a homogeneous mass was obtained. Photoconversion fluoropolymer films were drawn from the obtained gel. To determine the size of quantum dots, we used the method of dynamic light scattering, a Zetasizer Nano device (Malvern, PA, USA) [29], and TEM 200FE device (Carl Zeiss, Oberkochen, Germany) [30]. Optical absorption and photoluminescence were measured using high-speed spectrometers (OceanOptics, Largo, FL, USA) on optical devices described earlier [31]. A laboratory lighting system based on an XBO150W / 4 xenon lamp (OSRAM, Munich, Germany) with a power of $150 \mathrm{~W}$ was used as a light source. The spectral characteristics of the setup, under different operating conditions, including when using films, were recorded using a PM200 power and radiation energy meter (Thorlabs, Newton, NJ, USA).

\subsection{Plant Cultivation and Morphometry}

Influence of light converted by photoconversion fluoropolymer films. Morphometric parameters of plants were carried out in a climatic room. A number of experiments were carried out in greenhouses located in conditions of insufficient insolation ( $56^{\circ}$ north latitude). Plants were grown in the ground. Representatives of important agricultural crops were used as objects of research: paprika (Capsicum annuum L.), eggplant (Solanum melongena), common cucumber (Cucumis sativus), and tomato (Solanum lycopersicum). The main morphometric parameters were the length of the shoot and root, the number and area of leaves. The main morphometric parameters were determined using the GreenImage software developed by our team. The program is available for download (https://drive.google.com/open?id=1gcDcz1A9iGdd48YaXWO7duWMG263sotS). The principle of the program is as follows. Source RGB images of leaf plates of plant were obtained upright with the same distance from camera lens to leaf. To highlight the pixels corresponding to the image of the leafs, the following green highlighting procedure was applied:

$$
I_{G}=I_{g}+a I_{r}+b I_{b}
$$

where $I_{g}, I_{r}, I_{b}$ - the intensities of the RGB color components of the pixel, $I_{G}$-result intensity of highlighted green, $\mathrm{a}, \mathrm{b}$-weights. Then, threshold procedure was applied to determine leaf pixels. To estimate the area of sheets, the total number of pixels was normalized to the specific area of one pixel [32]. 


\section{Results}

The characteristics of nanosized fluorophores and polymers based on them, which produce photoconversion of UV radiation into the blue and red regions of the visible spectrum, have been investigated. The sizes of the obtained nanoparticles of fluorophores were investigated (Figure 1). Using the method of dynamic light scattering, it was shown that nanoparticles of a fluorophore emitting in the red spectral region have average size of about $7 \mathrm{~nm}$ (Figure 1a). Fluorophore nanoparticles emitting in the blue region of the spectrum have an average size of about $15 \mathrm{~nm}$ (Figure 1a). It was shown using TEM that fluorophore nanoparticles are predominantly spherical and weakly aggregate even on solid substrates (Figure 1b). It should be noted that the size obtained with the dynamic light scattering method and the TEM are the same. For implantation into a polymer film, the nanoparticles were placed in acetone.

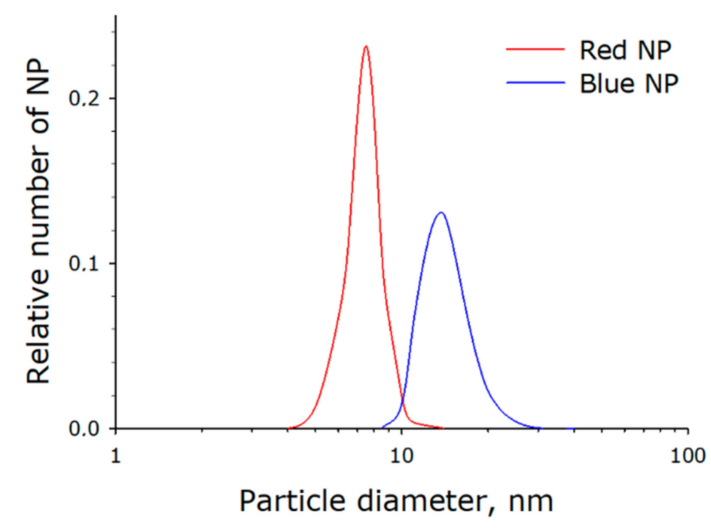

(a)

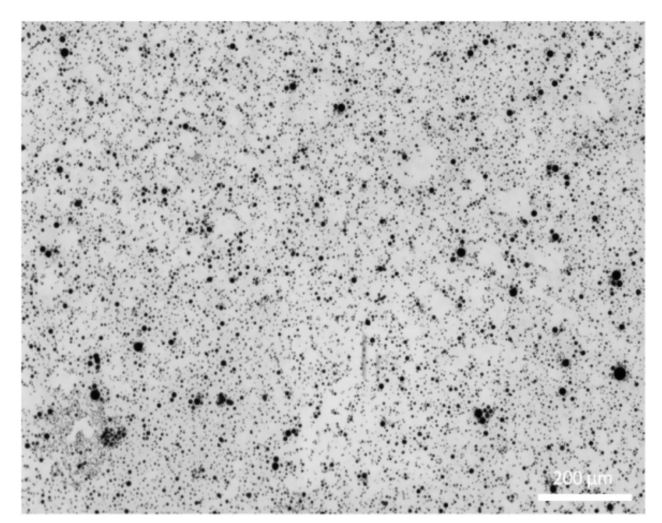

(b)

Figure 1. Size distribution of nanoparticles of fluorophores. (a) Size distribution of nanoparticles of fluorophores obtained using dynamic light scattering. Red NP-fluorophore nanoparticles with emission in the red region of the spectrum. Blue NP-fluorophore nanoparticles with blue emission. (b) TEM photograph of a preparation of a fluorophore containing nanoparticles with emission in both the red and blue spectral regions.

The photoluminescence spectra of nanoparticles in acetone and fluoropolymer were studied (Figure 2). In an analytical study of the emission of nanoparticles, excitation was performed using a diode-pumped solid-state laser at a wavelength of $375 \mathrm{~nm}$. As can be seen from Figure 2a, in photoluminescence, photons have an average energy of about $2 \mathrm{eV}$ (range 1.88-2.13 eV) and $2.7 \mathrm{eV}$ (range $2.47-2.83 \mathrm{eV}$ ). The determined quantum yields were $22 \%$ and $28 \%$. The recorded quantum yield of nanoparticles is comparable to the previously recorded quantum yield of nanoparticles of this type [33]. In the photoluminescence spectrum of a polymer film containing photoluminophores nanoparticles (Figure 2b), two maxima of luminescence are observed (450 and $655 \mathrm{~nm}$ ). In general, it can be argued that when using a light-converting composite film, we get light close to a black body with the imposition of "blue" and "red" components on it.

The effect of photoconversion fluoropolymer films on the growth rate of Capsicum annuum L., Solanum melongena, Cucumis sativus, and Solanum lycopersicum has been studied. It is shown that photoconversion polymer films increase the growth rate of all studied plants (Figure 3). For a quantitative assessment of the growth rate in plants, using the program we developed, the change in the area of leaf plates was estimated (Figure 4a). The median leaf area of Cucumis sativus grown under the photoconversion film is about $20 \%$ larger than the leaf area of control plants. The leaf area of pumpkin, pepper, and tomato grown under photoconversion film is 25,30 , and $55 \%$ higher, respectively, in comparison with control plants. The greatest influence on the growth rate is observed in tomato plants. Figure $4 \mathrm{~b}$ shows the dynamics of changes in the area of leaves of tomatoes grown under 
control film and photoconversion film. It was found that the leaf area of tomato plants grown under a photoconversion coating by the end of 4 weeks of growing season is significantly larger than in the control group. By the end of the fifth week of the growing season, the difference reaches, on average, almost $55 \%$.

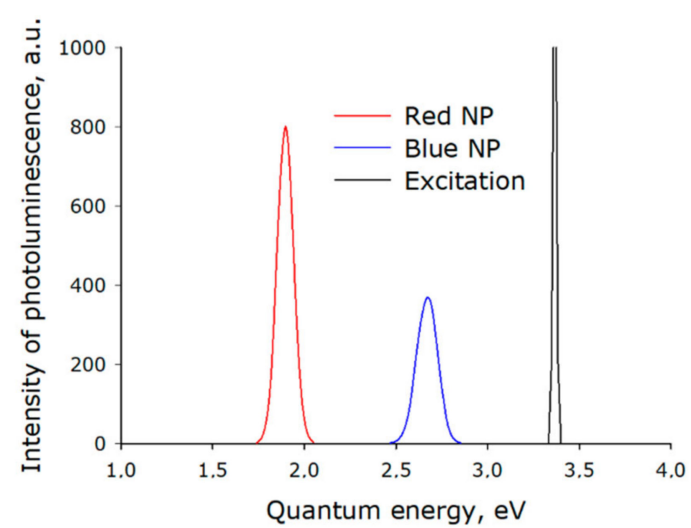

(a)

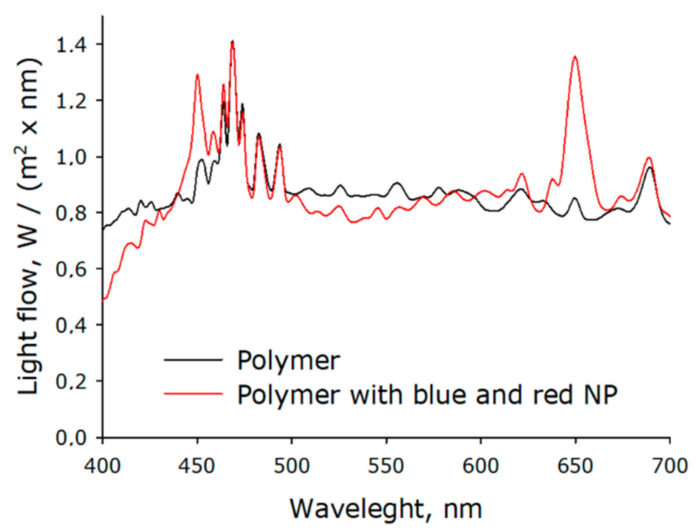

(b)

Figure 2. The photoluminescence spectrum of photoconversion nanoparticles. (a) Photoluminescence spectrum of photoconversion nanoparticles in acetone. Red NP-fluorophore nanoparticles with emission in the red region of the spectrum. Blue NP-fluorophore nanoparticles with blue emission. (b) The photoluminescence spectrum of a fluoropolymer containing and not containing photoconversion nanoparticles. Luminescence was excited with a xenon lamp and a diode source $(375 \mathrm{~nm})$.
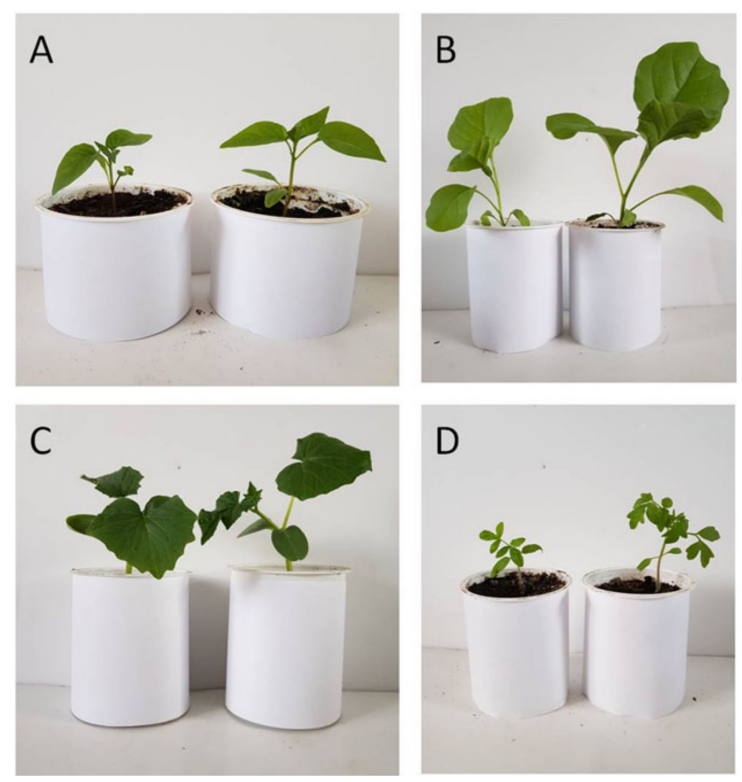

Figure 3. Effect of photoconversion polymer film on the size of plant leaves. Photographs of plants cultivated under a common (on the left of the image) and photoconversion (on the right of the image) film. (A) Capsicum annum L.; (B) Solanum melongena; (C) Cucumis sativus; (D) Solanum lycopersicum.

For most crops, biomass accumulation is often not a priority. More often, the weight of the fruits and its quality are much more important. In the case of tomatoes, the main indicator is the weight of the fruits from one bush. We grew tomato fruits in photoconversion coated greenhouses and control greenhouses (Figure 4a). In polycarbonate greenhouses (control greenhouses), about $7.6 \mathrm{~kg}$ of fruit (median weight) were collected from one bush (Figure $4 \mathrm{~b}$ ). When plants were grown under photoconversion polymer coatings, the median weight of fruits was about $8.7 \mathrm{~kg}$ per bush. Thus, in conditions of insufficient insolation, the use of photoconversion films makes it possible to obtain 
$15 \%$ more tomato fruits. As for the quality of the crop, it is difficult to assess it visually. We believe that tomatoes grown under photoconversion films did not differ significantly from tomatoes grown under control conditions. Photoconversion fluoropolymer films have the greatest effect on the development of plants of the Solanaceae family (Figures 3 and 4). It is known that the structure of the light harvesting complex may differ in different families and even genera of plants [34]. Obviously, with a change in the composition of photoluminophores, it is possible to achieve a greater accumulation of biomass not only in in plants of the Solanaceae family, but also in cultivated plants of other families. It is known that the structure and composition of the light harvesting complex of all plants undergo changes during ontogeny [35]. It follows from this that, in order to achieve the maximum efficiency of photosynthesis at different stages of ontogenesis, a change in the spectrum is necessary. It has been shown that the leaf area of tomato plants grown under a photoconversion coating is stably larger than that of control plants from the first weeks of life (Figure $4 \mathrm{~b}$ ). A total of 30 days after germination, the difference in the area of the leaf blades reaches almost $50 \%$. The weight of tomatoes per bush is significantly higher for plants grown under photoconversion film than for control plants. Probably, the spectrum of the photoconversion film developed by us is optimal for the growth of tomato plants, both at the stage of germination and at later stages of ontogenesis.

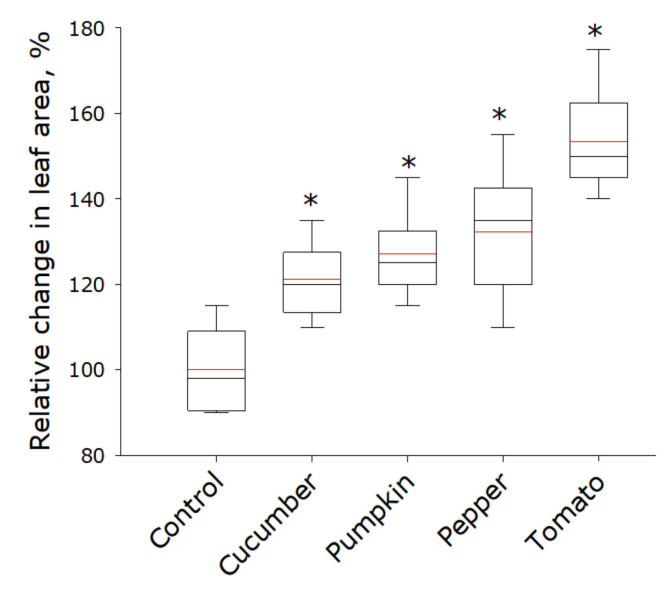

(a)

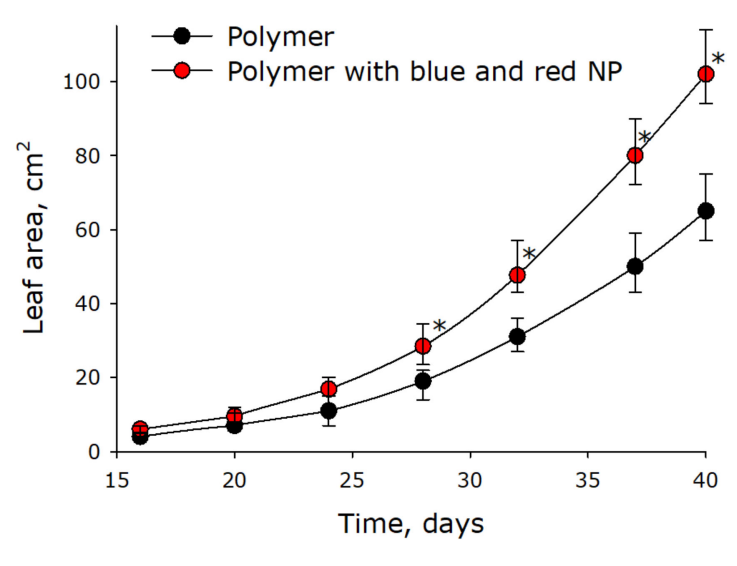

(b)

Figure 4. Influence of a photoconversion fluoropolymer film on the growth and development of plants of different species. (a) Effect of photoconversion polymer film on the leaf size of cucumber (Cucumis sativus), pumpkin (Cucurbita pepo), pepper (Capsicum annuum L.), tomato (Solanum lycopersicum) plants. Control values are normalized. Data are presented as median with $95 \%$ confidence interval (box). The range is shown in the form of a whiskers. Statistically significant differences between control group and other groups (Mann-Whitney $U$ test, $p<0.05$ ) are marked by asterisks. (b) Dynamics of changes in the leaf area of control tomato plants and tomato plants grown under a photoconversion polymer film. Statistically significant differences between control group and other groups (Mann-Whitney $U$ test, $p<0.05)$ are marked by asterisks.

\section{Discussion}

The idea of creating photoconversion films appeared more than thirty years ago [36]. At the first stage, films were created based on polyethylene and organic fluorophores. These films had a short life, the fluorophores degraded rather quickly. The next stage was the use of compounds based on rare earth elements as fluorophores [37]. These fluorophores were fairly persistent, but had a low quantum yield. A new generation of photoconversion films for greenhouses is created on the basis of nanoscale fluorophores and complex dyes [38-40]. There are also special films; for example, our team has developed a film in which two nanoscale fluorophores and gold nanoparticles are present as an additive. The film was developed for arctic conditions and allows not only photoconversion UV quantum to red quantum, but also the conversion of a part of the green quantum (little used by 
plants) into heat [27]. In this work, quantum dots are synthesized with a quantum yield of about $20 \%$, with emission in the blue $(460 \mathrm{~nm})$ and red $(650 \mathrm{~nm})$ spectral regions (Figures 1 and 2). Usually, most research uses fluorophores with an emission around $630 \mathrm{~nm}$. We know that the photosystems of higher plants operate at wavelengths close to $675-695 \mathrm{~nm}$ and $660-683 \mathrm{~nm}$. The more the wavelength of light differs from these values, the less efficient is the absorption of light quanta. For example, green quanta are absorbed significantly less efficiently than red ones. In this work, using the Pu \& Hsu method [28], we were able to make a fluorophore with an emission of $650 \mathrm{~nm}(20 \mathrm{~nm}$ closer to photosystems optimum).

It has been found that photoconversion films accelerate plant growth in the early stages of growth (Figures 3 and 4). Most of the works known to us also investigate the effect of converted radiation on the growth rate of plants in the early stages. Moreover, the effect of the converted sunlight on the rate of photosynthesis and various physiological parameters of plants is usually studied [41]. This manuscript focuses on all stages of plant development, including the fruiting stage. We have shown that the film developed by us allows us to increase the yield of plants (on average, each tomato bush brings more yield) (Figure 5). This is important not only from the point of view of technology and fundamental science, but can also have significant applied value.

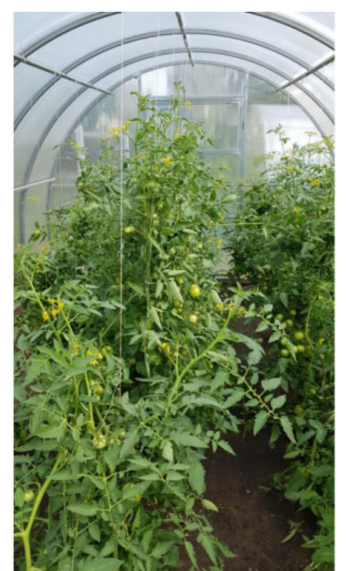

(a)

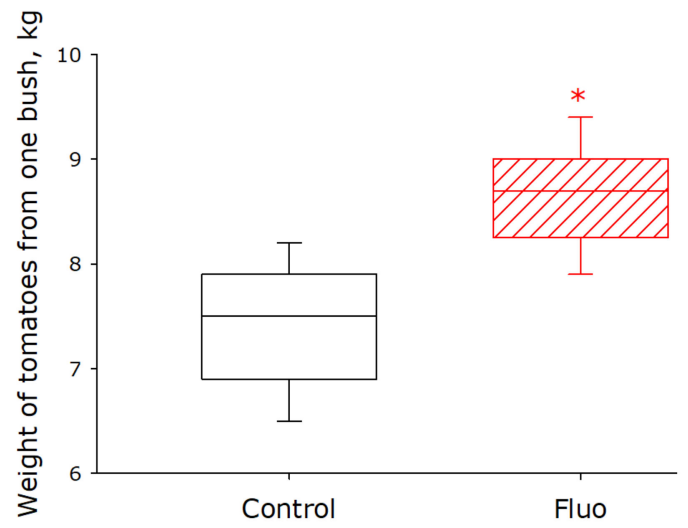

(b)

Figure 5. Influence of the photoconversion fluoropolymer film on the development of tomato plants. (a) Photo of tomatoes grown inside a greenhouse made from photoconversion polymer film. (b) Weight of tomato fruits harvested from one tomato bush grown under a control plastic film and photoconversion polymer film. Data are presented as median with $95 \%$ confidence interval (box). The range is shown in the form of a whiskers. Statistically significant differences between control group and other groups (Mann-Whitney $U$ test, $p<0.05$ ) are marked by asterisks.

\section{Conclusions}

The manuscript presents a technology for obtaining photoconversion fluoropolymer films for greenhouses based on nanoscale fluorophores with a high quantum yield. Films are capable of converting UV and violet radiation into the blue and red regions of the visible spectrum, the most important for plants. It is shown that the use of photoconversion fluoropolymer films promotes the growth of biomass. The leaf area of cucumber grown under photoconversion films increases by $20 \%$, pumpkin by $25 \%$, pepper by $30 \%$, and tomato by $55 \%$. The use of photoconversion fluoropolymer films for greenhouses also allows to obtain $15 \%$ more fruit biomass from one bush. In general, the use of photoconversion fluoropolymer films can be extremely beneficial for greenhouse farms located in high latitudes and located in places with insufficient insolation.

Author Contributions: A.V.S., V.V.I., A.S.D. were engaged in experimental work. S.V.G. and A.S.D. wrote the manuscript. All authors have read and agreed to the published version of the manuscript. 
Funding: This work was supported by a grant of the Ministry of Science and Higher Education of the Russian Federation for large scientific projects in priority areas of scientific and technological development (grant number 075-15-2020-774).

Acknowledgments: The authors are grateful to the Center for Collective Use of the GPI RAS for the equipment provided.

Conflicts of Interest: The authors declare no conflict of interest.

\section{References}

1. Duysens, L.N.M. Photosynthesis. Prog. Biophys. Mol. Biol. 1964, 14, 1-104. [CrossRef]

2. Des Marais, D.J. When Did Photosynthesis Emerge on Earth? Science 2000, 289, 1703-1705. [CrossRef]

3. Araujo, F.P.; Honorio, L.M.C.; Viana, B.C.; Silva-Filho, E.; Silva, F.W.N.; Furtini, M.B.; Araujo, M.R.; Souza, J.S.N.; Osajima, J.A. Understanding the role of dye in colorful thermoplastic film under visible light. J. Polym. Res. 2020, 27, 243. [CrossRef]

4. Powles, S.B. Photoinhibition of photosynthesis induced by visible light. Annu. Rev. Plant Physiol. 1984, 35, 15-44. [CrossRef]

5. Burchell, K.; Rhodes, L.E.; Webb, A.R. Public Awareness and Behaviour in Great Britain in the Context of Sunlight Exposure and Vitamin D: Results from the First Large-Scale and Representative Survey. Int. J. Environ. Res. Public Health 2020, 17, 6924. [CrossRef] [PubMed]

6. Catalán, J.; Papas, M.; Gacem, S.; Mateo-Otero, Y.; Rodríguez-Gil, J.E.; Miró, J.; Yeste, M. Red-Light Irradiation of Horse Spermatozoa Increases Mitochondrial Activity and Motility through Changes in the Motile Sperm Subpopulation Structure. Biology 2020, 9, 254. [CrossRef] [PubMed]

7. Chernov, A.S.; Reshetnikov, D.A.; Kovalitskaya, Y.A.; Manokhin, A.A.; Gudkov, S.V. Influence of wideband visible light with an padding red component on the functional state of mice embryos and embryonic stem cells. J. Photochem. Photobiol. B 2018, 188, 77-86. [CrossRef] [PubMed]

8. Gudkov, S.V.; Andreev, S.N.; Barmina, E.V.; Bunkin, N.F.; Kartabaeva, B.B.; Nesvat, A.P.; Stepanov, E.V.; Taranda, N.I.; Khramov, R.N.; Glinushkin, A.P. Effect of Visible Light on Biological Objects: Physiological and Pathophysiological Aspects. Phys. Wave Phenom. 2017, 25, 207-213. [CrossRef]

9. Karakatsouli, N.; Papoutsoglou, E.S.; Sotiropoulos, N.; Mourtikas, D.; Stigen-Martinsen, T.; Papoutsoglou, S.E. Effects of light spectrum, rearing density and light intensity on growth performance of scaled and mirror common carp Cyprinus carpio reared under recirculating system conditions. Aquac. Eng. 2010, 42, 121-127. [CrossRef]

10. Landi, M.; Zivcak, M.; Sytar, O.; Brestic, M.; Allakhverdiev, S.I. Plasticity of photosynthetic processes and the accumulation of secondary metabolites in plants in response to monochromatic light environments: A review. Biochim. Biophys. Acta Bioenerg. 2020, 1861, 148131. [CrossRef]

11. NobelPrize.org. The Nobel Prize in Physiology or Medicine 1903. Nobel Media AB 2020. Available online: https://www.nobelprize.org/prizes/medicine/1903/finsen/facts/ (accessed on 10 October 2020).

12. NobelPrize.org. The Nobel Prize in Physics 1964. Nobel Media AB 2020. Available online: https://www. nobelprize.org/prizes/physics/1964/summary/ (accessed on 10 October 2020).

13. Wu, B.S.; Hitti, Y.; MacPherson, S.; Orsat, V.; Lefsrud, M.G. Comparison and perspective of conventional and LED lighting for photobiology and industry applications. Environ. Exp. Bot. 2020, 171, 103953. [CrossRef]

14. Guryev, E.L.; Smyshlyaeva, A.S.; Shilyagina, N.Y.; Sokolova, E.A.; Shanwar, S.; Kostyuk, A.B.; Lyubeshkin, A.V.; Schulga, A.A.; Konovalova, E.V.; Lin, Q.; et al. UCNP-based Photoluminescent Nanomedicines for Targeted Imaging and Theranostics of Cancer. Molecules 2020, 25, 4302. [CrossRef] [PubMed]

15. Polikarpov, D.M.; Campbell, D.H.; McRobb, L.S.; Wu, J.; Lund, M.E.; Lu, Y.; Deyev, S.M.; Davidson, A.S.; Walsh, B.J.; Zvyagin, A.V.; et al. Near-Infrared Molecular Imaging of Glioblastoma by Miltuximab ${ }^{\circledR}$-IRDye800CW as a Potential Tool for Fluorescence-Guided Surgery. Cancers 2020, 12, 984. [CrossRef]

16. Chiu, Y.-H.; Chang, T.-F.M.; Chen, C.-Y.; Sone, M.; Hsu, Y.-J. Mechanistic Insights into Photodegradation of Organic Dyes Using Heterostructure Photocatalysts. Catalysts 2019, 9, 430. [CrossRef]

17. Melts, A.; Spangfort, M.; Andersson, B. Light-absorption and electron-transport balance between photosystem II and photosystem I in spinach chloroplasts. Photochem. Photobiol. 1987, 45, 129-136. [CrossRef] 
18. Singh, D.; Basu, C.; Meinhardt-Wollweber, M.; Roth, B. LEDs for energy efficient greenhouse lighting. Renew. Sust. Energy Rev. 2015, 49, 139-147. [CrossRef]

19. Mirkovic, T.; Ostroumov, E.E.; Anna, J.M.; Govindjee, R.; Scholes, G.D. Light Absorption and Energy Transfer in the Antenna Complexes of Photosynthetic Organisms. Chem. Rev. 2017, 117, 249-293. [CrossRef]

20. Petroutsos, D.; Tokutsu, R.; Maruyama, S.; Flori, S.; Greiner, A.; Magneschi, L.; Cusant, L.; Kottke, T.; Mittag, M.; Hegemann, P.; et al. A blue-light photoreceptor mediates the feedback regulation of photosynthesis. Nature 2016, 537, 563-566. [CrossRef]

21. Smith, H.L.; McAusland, L.; Murchie, E.H. Don't ignore the green light: Exploring diverse roles in plant processes. J. Exp. Bot. 2017, 68, 2099-2110. [CrossRef]

22. Stapleton, A.E. Ultraviolet Radiation and Plants: Burning Questions. Plant Cell. 1992, 4, 1353. [CrossRef]

23. Abdel-Ghany, A.M.; Al-Helal, I.M.; Alzahrani, S.M.; Alsadon, A.A.; Ali, I.M.; Elleithy, R.M. Covering Materials Incorporating Radiation-Preventing Techniques to Meet Greenhouse Cooling Challenges in Arid Regions: A Review. Sci. World J. 2012, 2012, 906360. [CrossRef] [PubMed]

24. Zhang, S.P.; Li, J.Y.; Chen, J.; Xiao, Y.; Sun, Y.E. Research of spectrum characteristics for light conversion agricultural films. Guang Pu Xue Yu Guang Pu Fen Xi 2004, 24, 1180-1184. [PubMed]

25. Wang, Y.; Yu, Y.; Liu, W.; Ren, L.; Ge, G. Exploration of Highly Efficient Blue-Violet Light Conversion Agents for an Agricultural Film Based on Structure Optimization of Triphenylacrylonitrile. J. Agric. Food Chem. 2018, 66, 13295-13302. [CrossRef] [PubMed]

26. Yu, Y.; Xu, P.; Jia, S.; Pan, H.; Zhang, H.; Wang, D.; Dong, L. Exploring polylactide/poly(butylene adipate-co-terephthalate)/rare earth complexes biodegradable light conversion agricultural films. Int. J. Biol. Macromol. 2019, 127, 210-221. [CrossRef]

27. Gudkov, S.V.; Simakin, A.V.; Bunkin, N.F.; Shafeev, G.A.; Astashev, M.E.; Glinushkin, A.P.; Grinberg, M.A.; Vodeneev, V.A. Development and application of photoconversion fluoropolymer films for greenhouses located at high or polar latitudes. J. Photochem. Photobiol. B 2020, 213, 112056. [CrossRef]

28. Pu, Y.C.; Hsu, Y.J. Multicolored Cd(1-x)Zn(x)Se quantum dots with type-I core/shell structure: Single-step synthesis and their use as light emitting diodes. Nanoscale 2014, 6, 3881. [CrossRef]

29. Gudkov, S.V.; Guryev, E.L.; Gapeyev, A.B.; Sharapov, M.G.; Bunkin, N.F.; Shkirin, A.V.; Zabelina, T.S.; Glinushkin, A.P.; Sevost'yanov, M.A.; Belosludtsev, K.N.; et al. Unmodified hydrated C60 fullerene molecules exhibit antioxidant properties, prevent damage to DNA and proteins induced by reactive oxygen species and protect mice against injuries caused by radiation-induced oxidative stress. Nanomedicine 2019, 15, 37-46. [CrossRef]

30. Simakin, A.V.; Astashev, M.E.; Baimler, I.V.; Uvarov, O.V.; Voronov, V.V.; Vedunova, M.V.; Sevost'yanov, M.A.; Belosludtsev, K.N.; Gudkov, S.V. The Effect of Gold Nanoparticle Concentration and Laser Fluence on the Laser-Induced Water Decomposition. J. Phys. Chem. B 2019, 123, 1869-1880. [CrossRef]

31. Barmina, E.V.; Gudkov, S.V.; Simakin, A.V.; Shafeev, G.A. Stable Products of Laser-Induced Breakdown of Aqueous Colloidal Solutions of Nanoparticles. J. Laser Micro Nanoeng. 2017, 12, 254. [CrossRef]

32. Gudkov, S.V.; Shafeev, G.A.; Glinushkin, A.P.; Shkirin, A.V.; Barmina, E.V.; Rakov, I.I.; Simakin, A.V.; Kislov, A.V.; Astashev, M.E.; Vodeneev, V.A.; et al. Production and Use of Selenium Nanoparticles as Fertilizers. ACS Omega 2020, 5, 17767-17774. [CrossRef]

33. Fitzmorris, B.C.; Pu, Y.C.; Cooper, J.K.; Lin, Y.F.; Hsu, Y.J.; Li, Y.; Zhang, J.Z. Optical properties and exciton dynamics of alloyed core/shell/shell Cd(1-x)Zn(x)Se/ZnSe/ ZnS quantum dots. ACS Appl. Mater. Interfaces 2013, 5, 2893-2900. [CrossRef] [PubMed]

34. Neilson, J.A.D.; Durnford, D.G. Structural and functional diversification of the light-harvesting complexes in photosynthetic eukaryotes. Photosynth. Res. 2010, 106, 57-71. [CrossRef]

35. Carvalho, F.E.L.; Ware, M.A.; Ruban, A.V. Quantifying the dynamics of light tolerance in Arabidopsis plants during ontogenesis. Plant Cell Environ. 2015, 38, 2603-2617. [CrossRef] [PubMed]

36. Schelokov, R.N. Polysvetanes and polysvetane effect. Herald Russ. Acad. Sci. 1986, 10, 50-55.

37. Palkina, K.K.; Kuz'mina, N.E.; Strashnova, S.B.; Goncharov, O.V.; Shchelokov, R.N. Synthesis and structure of the 2-Amino-3-Hydroxypyridine complexes with trivalent praseodymium, neodymium, samarium, and europium nitrates: Crystal structure of Tris (2-Amino-3-Hydroxypyridine) trinitratosamarium (III) monohydrate. Russ. J. Inorg. Chem. 2000, 45, 515-520.

38. El-Bashira, S.M.; Al-Jaghwanic, A.A. Perylene-doped polycarbonate coatings for acrylic active greenhouse luminescent solar concentrator dryers. Results Phys. 2020, 16, 102920. [CrossRef] 
39. El-Bashir, S.M.; AlSalhi, M.S.; Al-Faifi, F.; Alenazi, W.K. Spectral properties of PMMA films doped by perylene dyestuffs for photoselective greenhouse cladding applications. Polymers 2019, 11, 494. [CrossRef] [PubMed]

40. Khramov, R.N.; Kreslavski, V.D.; Svidchenko, E.A.; Surin, N.M.; Kosobryukhov, A.A. Influence of photoluminophore-modified agro textile spunbond on growth and photosynthesis of cabbage and lettuce plants. Opt. Express 2019, 27, 31967-31977. [CrossRef] [PubMed]

41. Pearson, S.; Wheldon, A.E.; Hadley, P. Radiation Transmission and Fluorescence of Nine Greenhouse Cladding Materials. J. Agric. Eng. Res. 1995, 62, 61-69. [CrossRef]

Publisher's Note: MDPI stays neutral with regard to jurisdictional claims in published maps and institutional affiliations.

(C) 2020 by the authors. Licensee MDPI, Basel, Switzerland. This article is an open access article distributed under the terms and conditions of the Creative Commons Attribution (CC BY) license (http://creativecommons.org/licenses/by/4.0/). 